\title{
Wireless Power Transfer System Design with Power Management Strategy Control for Lunar Rover
}

\author{
Bingcheng Ji ${ }^{* a)}$ \\ Takehiro Imura** \\ Non-member, \\ Katsuhiro Hata* \\ Member \\ Shuhei Shimada ${ }^{* * *+}$ \\ Member, \\ Yoichi Hori* $^{*}$ \\ Fellow \\ Non-member, \\ Osamu Kawasaki**** \\ Non-member
}

(Manuscript received July 26, 2019, revised Dec. 17, 2019)

\begin{abstract}
To avoid heat leakage from a lunar rover during lunar night, this paper proposes a wireless power transfer (WPT) system to replace the wire connection between the PV panel and rover body. The WPT system is powered by a PV panel, and the generated power can be transferred to the rover body via magnetic coupling. The rover side load is connected with a DC bus, and its voltage is stabilized by a DC-DC converter. Based on this topology, a power management strategy for the proposed WPT system is also proposed. According to the variation in the solar irradiance and rover side power requirement, the PV panel can be controlled in different working modes automatically to output the appropriate power. A 45-W experimental platform is established, and the experimental results show that the proposed system can automatically switch the working mode based on the solar irradiance and power requirement. When the power is $45 \mathrm{~W}$, the total efficiency of the system is approximately 75\%. The experimental results show that the proposed WPT system and power management strategy are effective and can be employed in the future.
\end{abstract}

Keywords: heat leakage, lunar rover, power management strategy, PV panel, wireless power transfer

\section{Introduction}

For a long time, the investigation of the Moon has achieved great developments, and various lunar rovers have been launched to the surface of the Moon to explore the lunar environment $^{(1)}$. As the power source in lunar rovers, the PV panel can convert solar energy into electricity and the output power-voltage $(\mathrm{P}-\mathrm{V})$ characteristic possesses only one peak $^{(2)}$. Therefore, to make full use of solar energy, the maximum power point tracking (MPPT) of the PV panel should be conducted ${ }^{(3)}$. For PV MPPT control, numerous algorithms have been developed, such as constant voltage $(\mathrm{CV})^{(4)(5)}$, perturb and observe $(\mathrm{P} \& \mathrm{O})^{(6)(7)}$ and incremental conductance (IC)methods ${ }^{(8)(9)}$. In the CV method, MPPT can be conducted by controlling the output voltage as the optimal value but the value should be known in advance ${ }^{(4)}$. The P\&O method is conducted by adjusting a small amount of the PV output voltage and then tracking the working point toward the direction

a) Correspondence to: Bingcheng Ji. E-mail: ki.heisei17@ae.k. u-tokyo.ac.jp

* Department of Advanced Energy, Graduate School of Frontier Sciences, University of Tokyo

5-1-5, Kashiwa, Chiba 277-8561, Japan

${ }^{* *}$ Department of Informatics and Electronics, Institute of Industrial Science, University of Tokyo

4-6-1, Komaba, Meguro-ku, Tokyo 153-8505, Japan

*** Department of Electrical Engineering, Tokyo University of Science

2641, Yamazaki, Chiba 278-8510, Japan

${ }^{* * * *}$ Reseach Unit I, R\&D Directorate, Japan Aerospace Exploration Agency

2-1-1, Sengen, Tsukuba, Ibaraki 305-8505, Japan in the PV curve that can increase the output power. Therefore, there would be oscillations in the output power ${ }^{(6)}$. The IC method can track the maximum power point by using the PV battery incremental conductance to calculate the current working point in the PV curve. Because the IC method can track the maximum power point without oscillations, it has been employed in cases that require higher accuracy and stability ${ }^{(8)}$. Apart from the aforementioned three main algorithms, various new methods have been developed, such as particle swarm optimization (PSO) ${ }^{(10)}$, the flower pollination algorithm (FPA) ${ }^{(11)}$, and the firefly algorithm (FA) ${ }^{(12)}$. These algorithms can cope with more complex working situations and the tracking accuracy can be improved. However, the computational cost also increases sharply, which is not really applicable to the case of a lunar rover.

In conventional lunar rover designs, the PV panel is connected to the rover side through wire connection as shown in Fig. 1(a), and the wire connection requires a slit on the thermal insulation materials used to encase the rover body. During lunar day, the power generated by the PV panel can be transferred to the rover body side equipment, and during lunar night, the PV panel stops working. In particular, the Moon surface temperature is lower than $-200^{\circ} \mathrm{C}$ during lunar night but the rover internal equipment should be warmed to room temperature by the thermal control system. Then, during lunar night there will be a heat leakage along the wire to the outside in Fig. 1(b). To stabilize the rover internal temperature, the leaked heat should be covered by the battery, which means the battery volume should be increased. For the lunar rover considered in this study, the heat leakage power during lunar night is approximatedly $20 \mathrm{~W}$, and then an extra 


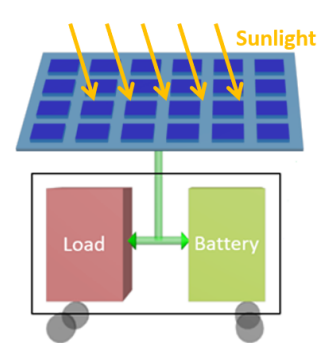

(a)

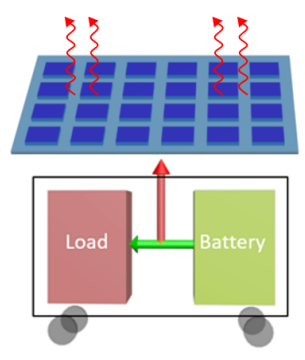

(b)

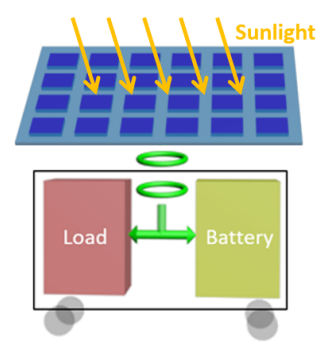

(c)

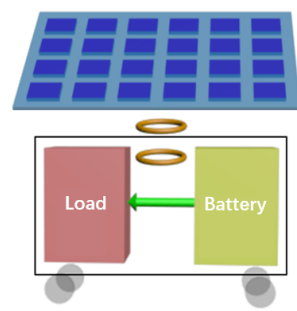

(d)

Fig. 1. (a) Conventional structure at lunar day. (b) Conventional structure at. (c) Proposed structure at lunar day. (d) Proposed structure at lunar night

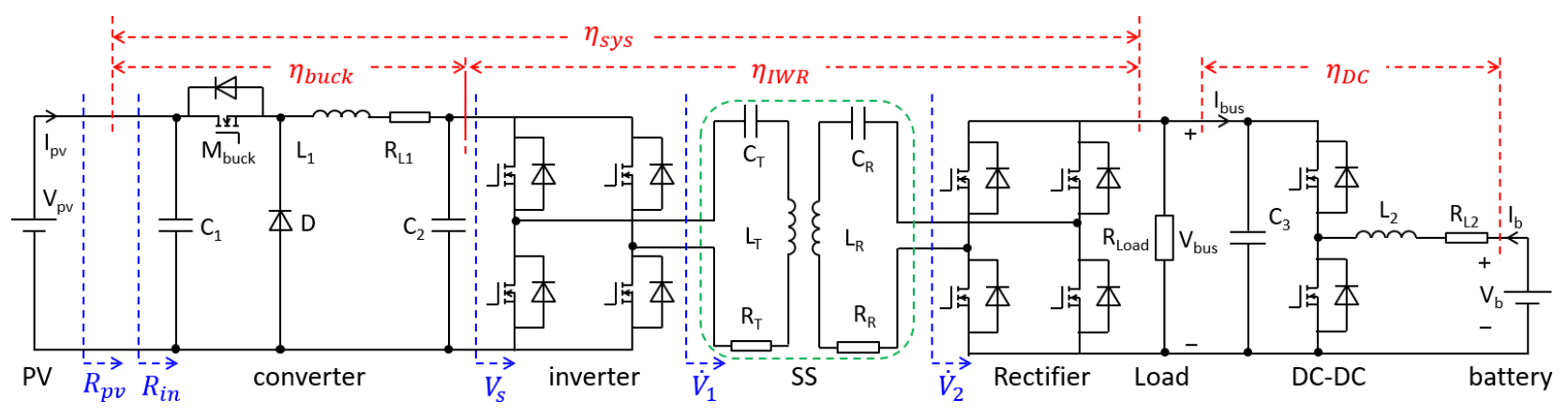

Fig. 2. Proposed lunar rover WPT system topology

$40 \mathrm{~kg}$ battery pack should be added. Then, the extra required battery volume will lead to a large cost and burden for the rocket launch. Therefore, it is urgent and necessary for a lunar rover to avoid heat leakage.

In recent years, wireless power transfer (WPT) ${ }^{(13)}$ has been developed all over the world. Because WPT can bring about various advantages in terms of convenience and safety, there have been numerous developments ${ }^{(14)-(16)}$, such as electric vehicles $(\mathrm{EVS})^{(17)-(19)}$, medical implants ${ }^{(20)-(22)}$ and the Internet of Things (IoT) ${ }^{(23)-(25)}$. In general, in a WPT system, power can be transferred from a transmitter coil to a receiver coil through magnetic coupling, and the main WPT circuit can be divided into series-series (SS), series-parallel (SP), parallelseries (PS) and parallel-parallel (PP) topologies ${ }^{(26)}$. Among these topologies, the SS topology possesses constant reactance looking from the transmitter side, which is independent of the mutual inductance and receiver side resonance frequency. So far, to the best of our knowledge, WPT research has not been carried out for a lunar rover, and it may be an effective solution to the lunar rover heat leakage issue.

Based on the above analysis, a novel WPT system for a lunar rover and its power management strategy are proposed in this paper. The rest of this paper is organized as follows: Section 2 proposes the system structure and topology design. Section 3 conducts the PV panel power control. Section 4 explores the WPT design and the DC-DC converter control. Section 5 conducts the receiver side DC bus voltage control. Section 6 validates the designed WPT system with experiments. Finally, section 7 presents the conclusion.

\section{Proposed System Structure and Topology}

There are two key requirements of the lunar rover PV power system. During lunar day, the generated power from the PV panel should be transferred to the rover side instruments, and during lunar night, there should be no heat leakage from the rover body to the outside. Because the heat leakage in conventional structures is mainly caused by the slit on thermal insulation materials, in this paper a WPT system is proposed.

The proposed WPT system is shown in Figs. 1(c) and (d). The transmitter side is connected to the PV panel, and the receiver side is placed in the rover body. Therefore, in this way, the conventional wire connection can be replaced with the WPT system, and then the slit on the thermal proof materials can be avoided. During lunar day the generated power from the PV panel can be transferred from the transmitter coil to the receiver coil based on magnetic coupling. During the lunar night, because there is no slit on the thermal proof materials, the heat leakage caused by the thermal conduction along the wire connection can be completely avoided. In this way, there will be no extra requirement of the rover battery volume and the launch cost can be reduced.

With the above analysis, the proposed lunar rover WPT system circuit topology is shown in Fig. 2. For the transmitter side, the PV output power is controlled by a converter considering various solar irradiances. Under working conditions, the PV panel can be controlled to work in the MPPT mode to output the maximum power or the other mode to output the optimal amount of power. For the WPT part, in order to avoid the unnecessary circuit devices to reduce the WPT weight, the SS topology is employed. For the receiver side, the load $R_{L}$ is connected to the DC bus and in this paper the load is purely resistive. The DC bus voltage is controlled by a bidirectional DC-DC converter. Therefore, the battery can be employed to balance the system power supply from the PV and the requirements from the load by outputting/absorbing power to/from the DC bus when the PV generated power is insufficient/excessive. When the solar irradiance or power requirement changes, the system should be controlled by a power management strategy to work in different modes. 


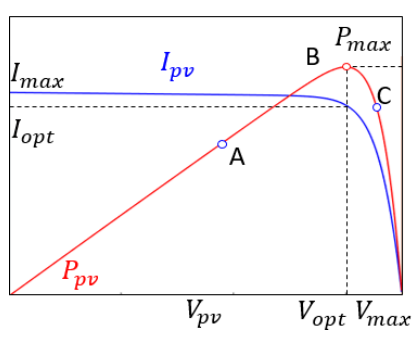

(a)

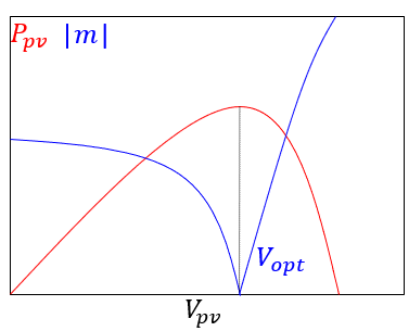

(b)

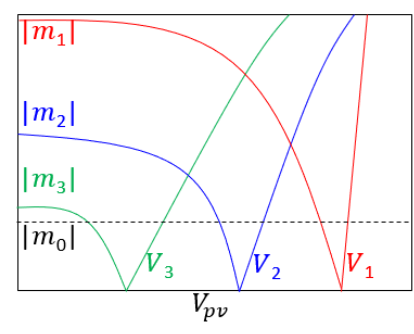

(c)

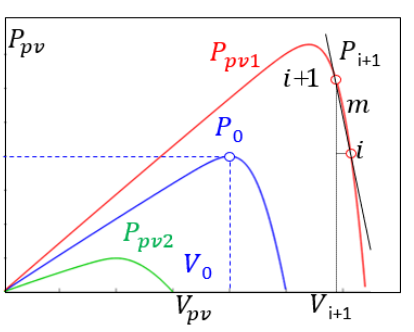

(d)

Fig. 3. (a) PV output characteristics. (b) P-V curve derivative. (c) P-V curve derivatives in different conditions.

(d) Calculation for various coefficients

\section{PV Panel Output Power Control}

In this paper, the PV is the only power source for the lunar rover, and the output power should be controlled according to the solar irradiance variation and rover side power requirement. Therefore, the following two modes are proposed.

3.1 Maximum Power Point Tracking Mode In this section, a novel IC method is employed to conduct the MPPT control. The PV property is shown in Fig. 3(a), and there is only one peak for the PV curve at different output voltages. Therefore, the derivative of the PV curve can be obtained.

$$
m=\frac{d P}{d V}=\frac{d(V I)}{d V}=I+V \frac{d I}{d V}
$$

At positions A, B and C, the derivatives are positive, zero and negative, respectively. Therefore, based on the derivative calculation in real time, MPPT can be conducted by tuning the PV buck converter duty to control the PV output voltage to track $V_{o p t}$. As the PV output power increases, the absolute value of the derivative $|d P / d V|$ decreases to zero gradually in Fig. 3(b), and then the varying duty step can be obtained as follows.

$$
d(k)=d(k-1) \pm \Delta d=d(k-1) \pm N_{0}\left|\frac{d P}{d V}\right| \cdots \cdots(2)
$$

In the equation, $N_{0}$ is a constant coefficient. In the conventional variant step IC method, the algorithm step is always tuned only based on $|d P / d V|^{(28)-(30)}$. Then the step tuning effect is only related to the derivative value and different PV properties will be coped with same tuning handling. For example, as shown in Fig. 3(c), considering various PV curves, $|d P / d V|$ decreases to zero at different speeds. Taking $\left|m_{2}\right|$ as a standard, with higher $P_{\max } / V_{\text {opt }}$ such as $\left|m_{1}\right|$, the derivative valley is much narrower than that of $\left|m_{2}\right|$. Similarly, with a lower $P_{\text {max }} / V_{\text {opt }}$, the derivative valley of $\left|m_{3}\right|$ becomes wider. Defining the valley under $\left|m_{0}\right|$ as the peak area, then the tracking step should be reduced for $P_{p v 1}$ to improve the tracking accuracy and increased for $P_{p v 2}$ to accelerate the tracking speed. In other words, the step variation should be controlled to be lower for higher $P_{\text {max }} / V_{o p t}$ PV curves and higher for lower $P_{\text {max }} / V_{\text {opt }}$ PV curves. In Eq. (2), only the employment of $|d P / d V|$ can not meet the step variation requirement.

Therefore, in this paper, the PV peak height of $\left|P_{\text {max }} / V_{\text {opt }}\right|$ is employed to further tune the variance step. The solar irradiance of the position on the Moon surface where lunar rover is going to be launched can be estimated in advance, and then the average PV power $P_{0}-V_{0}$ is taken as the standard in Fig. 3(d). Under working conditions, the derivative $\left|m_{0}\right|$ is set

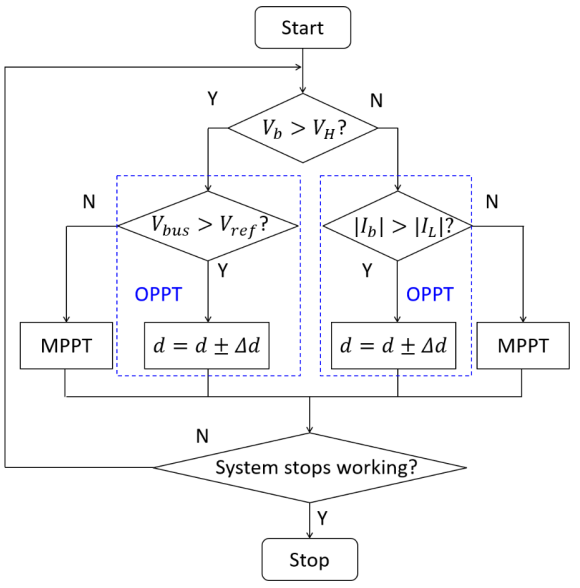

Fig. 4. PV OPPT mode flowchart

as the valley entrance standard. When $|m|$ is lower than $\left|m_{0}\right|$, it can be concluded the working point enters the peak area. In the peak area, the ratio of the power and voltage $P / V$ varies with different PV curves. For the curve $P_{p v 1}, P / V$ is higher than $P_{0} / V_{0}$, and for the curve $P_{p v 3}, P / V$ is lower than $P_{0} / V_{0}$. Therefore, the ratio $P / V$ can be employed to tune the varying step in Eq. (3).

$$
\begin{cases}\Delta d=N_{0}\left|\frac{d P}{d V}\right| & \text { if }|m|>\left|m_{0}\right| \\ \Delta d=N_{0}\left|\frac{d P}{d V}\right| \frac{P_{0} / V_{0}}{P / V} & \text { if }|m|<=\left|m_{0}\right|\end{cases}
$$

In this way, the step $\Delta d$ can be reduced for $P_{p v 1}$ and increased for $P_{p v 2}$ in peak area. Therefore, the PV panel varying step MPPT control can be conducted.

3.2 Optimal Power Point Tracking Mode When the solar irradiance is too strong or the rover side power requirement decreases, the PV should stop MPPT mode to reduce the output power. In PV applications such as a power grid or a household microgrid, the PV panel is directedly connected to the load side ${ }^{(27)}$. Therefore, when the power requirement decreases, the PV panel can be controlled to change from MPPT mode to buck mode. In buck mode, the PV output voltage can be controlled to the required level and then the output power can be reduced. However, in this paper, the PV module (including the PV and buck converter) is connected to the DC bus through the WPT module. When the battery is connected to the DC bus, the DC bus voltage $V_{\text {bus }}$ can be controlled by a DC-DC converter regardless of the PV working modes. However, when the battery is switched off, $V_{\text {bus }}$ should be controlled only by the PV buck converter. In this case, the conventional buck mode cannot control $V_{b u s}$. 


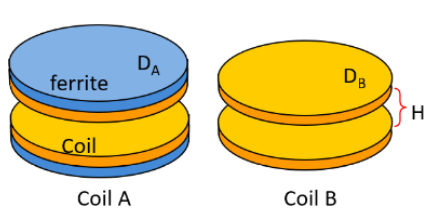

(a)

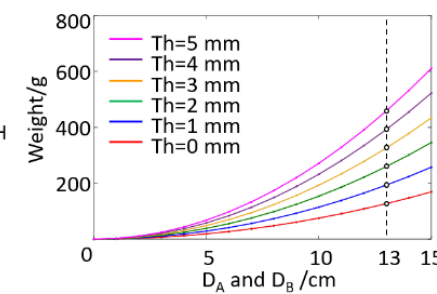

(b)

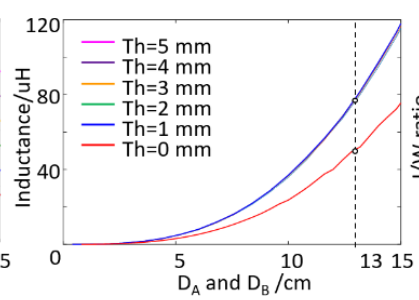

(c)

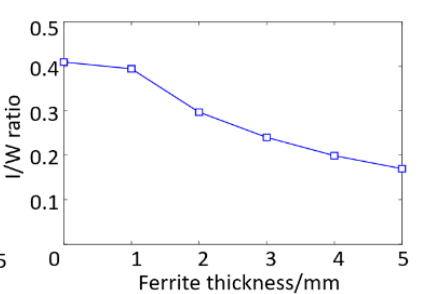

(d)

Fig. 5. WPT coils design (a) Coil structure design. (b) Coil weight simulation. (c) Coil inductance simulation. (d) Ferrite improvement analysis

Therefore, an optimal power point tracking (OPPT) method is proposed and the flowchart is shown in Fig. 4.

To protect the battery, the battery voltage and charge current limits are set as $\left[V_{L}, V_{H}\right]$ and $\left[I_{L}, I_{H}\right]$, respectively. $I_{L}$ and $I_{H}$ are the battery charge and discharge current limits, and the battery current $I_{b}$ is positive when the battery discharges. Furthermore, when $V_{b}>V_{H}$ which indicates that the battery has been fully charged, it should be switched off from the DC bus.

\section{a. With the battery connected to the DC bus}

When the battery voltage $V_{L}<V_{b}<V_{H}, V_{b u s}$ can be controlled by the DC-DC converter. In this case, when the battery charge current is higher than the limit, namely $\left|I_{b}\right|>\left|I_{L}\right|$, the system will move from MPPT mode to OPPT mode. As shown in Fig. 4, the buck converter duty is modified to increase or decrease to limit the battery current to $I_{b}$.

b. With the battery switched off from the DC bus

When the battery voltage $V_{b}>V_{H}$, the battery should be switched off. In this case the DC-DC converter cannot be used to stabilize $V_{\text {bus }}$, and only the PV buck converter should be employed. Therefore, $V_{b u s}$ determines the system working mode as shown in Fig. 4. In MPPT mode, if $V_{b u s}$ is higher than the required value, the system will move to OPPT mode. The buck converter duty will be tuned to increase or decrease based on $V_{b u s}$ until the reference is approached.

\section{WPT Design and DC-DC Converter Control}

In this paper, the SS topology shown in Fig. 2 is adopted. The power can be transferred from the transmitter coil to the receiver coil via magnetic coupling.

\subsection{WPT Coil Design and Parameters For WPT} systems, the coil is one of the most important devices that can influence the transferred power and efficiency. As the lunar rover is transported to the Moon surface by a rocket, the coil weight and size should be the key factors in the WPT system design. In this paper, the coil should be designed within a cylindrical space and the maximum diameter is $130 \mathrm{~mm}$. In Fig. 5(a), the coil structure with ferrite named coil A and the coil without ferrite named coil B are focused. The diameters of coils $\mathrm{A}$ and $\mathrm{B}$ are $D_{A}$ and $D_{B}$, respectively, and the coil distance is $H$. The litz wire diameter is $2 \mathrm{~mm}$, and the ferrite module thickness also varies from 1 to $5 \mathrm{~mm}$. The weight and inductance simulations are conducted with JMAG, which is a simulation software for the development and design of electrical devices.

The weight and inductance simulations of coil A (with a ferrite thickness varying from 1 to $5 \mathrm{~mm}$ ) and coil B are shown in Figs. 5(b) and (c). It can be concluded that the
Table 1. Ferrite property simulation

\begin{tabular}{c|c|c|c|c|c|c}
\hline Thickness/mm & 0 & 1 & 2 & 3 & 4 & 5 \\
\hline Weight/g & 125 & 196 & 260 & 328 & 393 & 458 \\
\hline $\mathrm{L} / \mathrm{uH}$ & 51.2 & 75.3 & 77.6 & 78.1 & 78.3 & 78.5 \\
\hline$L / w$ & 0.41 & 0.38 & 0.29 & 0.23 & 0.19 & 0.17 \\
\hline
\end{tabular}

Table 2. WPT module parameters

\begin{tabular}{c|c|c|c}
\hline Symbol & Quantity & Symbol & Quantity \\
\hline$f / \mathrm{kHz}$ & 85 & $R_{2} / \mathrm{m} \Omega$ & 345.9 \\
\hline$R_{1} / \mathrm{m} \Omega$ & 352.1 & $L_{2} / \mu \mathrm{H}$ & 50.2 \\
\hline$L_{1} / \mu \mathrm{H}$ & 50.1 & $C_{2} \mathrm{nF}$ & 71.1 \\
\hline$C_{1} / \mathrm{nF}$ & 71.3 & $k$ & 0.28 \\
\hline$r_{\text {wire }} / \mathrm{mm}$ & 1 & turns & 32 \\
\hline
\end{tabular}

ferrite materials bring about a severe weight burden to the coils. For example, with the diameter as $130 \mathrm{~mm}$, coil A with a 1-mm-thick ferrite and coil B are $196 \mathrm{~g}$ and $125 \mathrm{~g}$, respectively. Furthermore, the 1-mm-thick ferrite can result in magnetic saturation and thicker ferrite materials cannot bring about an inductance enhancement. Based on the simulation results, Table 1 and Fig. 5(d) can be obtained. The ratio of the coil inductance and weight $L / w$ is employed to assess the ferrite enhancement. From Fig. 5(d), with thicker ferrite materials, $L / w$ is reduced, but for 1-mm-thick ferrite, coil A $L / w$ is also lower than that of coil $\mathrm{B}$. Therefore, for a higher inductance 1-mm-thick ferrite can be employed, but the weight burden is a severe issue.

Considering the lunar rover power requirements, because there are approximately 336 hours of a lunar day, the rover battery can be charged for a sufficient length of time. Therefore, compared with the inductance enhancement, the weight burden caused by the ferrite materials is more significant. Furthermore, because the temperature during lunar night is really low, the magnetic enhancement of the ferrite materials will be sharply reduced. Therefore, in this paper, the ferrite module is not used, namely the coil B has been employed. The coil diameter is set as $130 \mathrm{~mm}$ and due to the space limit, the coil distance is $H=30 \mathrm{~mm}$. With the designed coil, the SS structure parameters are shown in Table 2.

4.2 WPT Efficiency with A Constant DC Bus Voltage

The SS topology is shown in Fig. 6(a), and based on the circuit, the following equation can be obtained.

$$
\left(\begin{array}{c}
\dot{V}_{1} \\
0
\end{array}\right)=\left(\begin{array}{cc}
R_{1} & -j \omega M \\
-j \omega M & R_{2}+R_{L}
\end{array}\right)\left(\begin{array}{c}
\dot{I}_{1} \\
\dot{I}_{2}
\end{array}\right) \ldots \ldots \ldots \ldots \ldots \ldots
$$

Therefore, the WPT efficiency is obtained as follows.

$$
\eta=\frac{\omega^{2} M^{2} R_{L}}{\left(R_{2}+R_{L}\right)\left(R_{1} R_{2}+R_{1} R_{L}+\omega^{2} M^{2}\right)}
$$




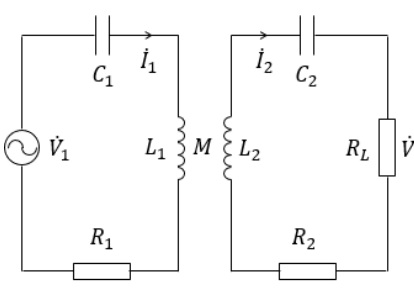

(a)

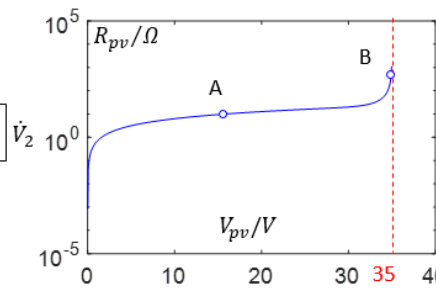

(b)

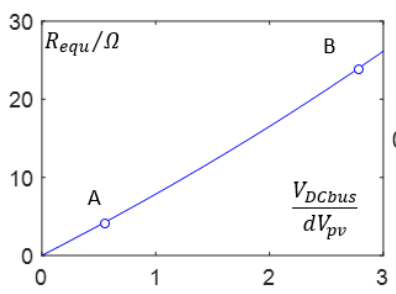

(c)

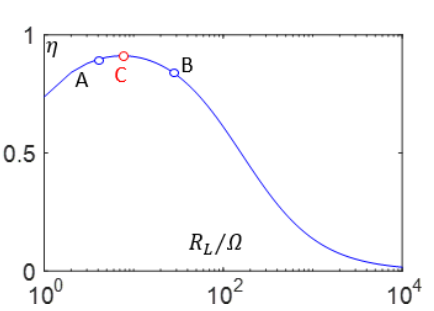

(d)

Fig. 6. WPT efficiency analysis (a) SS topology. (b) PV panel output resistance. (c) Equivalent resistance with constant DC bus voltage. (d) WPT efficiency

The derivative of $\eta$ is calculated and the maximum efficiency $\eta_{\max }$ can be obtained.

$$
\left\{\begin{array}{l}
R_{L \_\eta \max }=\sqrt{R_{2}\left(\frac{\omega^{2} M^{2}}{R_{1}}+R_{2}\right)} \\
\eta_{\max }=\frac{\omega^{2} M^{2} R_{L \_\eta \max }}{\left(R_{2}+R_{L \_\eta \max }\right)\left(R_{1} R_{2}+R_{1} R_{L \_\eta \max }+\omega^{2} M^{2}\right)}
\end{array}\right.
$$

Therefore, with the employed WPT module in Table 2, the maximum efficiency is $\eta_{\max }=91.11 \%$ with an optimal resistor of $R_{L \_\eta \max }=7.42 \Omega$.

However, under working conditions, the PV output voltage varies with different working points but the DC bus voltage is constant. Therefore, the load $R_{L}$ whose voltage is controlled by the DC-DC converter is equivalent to a varying load $R_{\text {equ }}$, which can obtain a constant load voltage without DC-DC converter stabilization. Therefore, it is necessary to analyze the WPT module efficiency with the equivalent load $R_{\text {equ }}$.

From Fig. 2, the PV output resistance $R_{p v}$ and system input resistance $R_{\text {in }}$ can be obtained.

$$
R_{p v}=\frac{V_{p v}}{I_{p v}}, \quad R_{i n}=\frac{\pi^{2}}{8 d_{p v}^{2}}\left(R_{1}+\frac{\omega^{2} M^{2}}{R_{2}+8 R_{L} / \pi^{2}}\right) \cdots
$$

In the equation, $d_{p v}$ is the buck converter duty. $R_{p v}$ is related to PV curves and Fig. 6(b) is based on the PV curve in Fig. 3(a). In this paper, the buck converter duty is limited from 0.1 at position B to 0.9 at position A. Therefore, the $R_{p v}$ and $V_{p v}$ ranges can be obtained.

$$
\left\{\begin{array}{l}
R_{p v} \in[10.59 \Omega(A), 858.41 \Omega(B)] \\
V_{p v} \in[16.8 V(A), 34.9 V(B)]
\end{array}\right.
$$

Furthermore, the WPT transform is shown in Eq. (9).

$$
A_{V}=\frac{\dot{V}_{2}}{\dot{V}_{1}}=j \frac{\omega M R_{L}}{R_{1} R_{2}+R_{1} R_{L}+\omega^{2} M^{2}}
$$

Furthermore, the following equations can also be obtained.

$$
\left|\dot{V}_{1}\right|=\frac{2 \sqrt{2}}{\pi} V_{S}=d_{p v} \frac{2 \sqrt{2}}{\pi} V_{p v}, \quad\left|\dot{V}_{2}\right|=\frac{2 \sqrt{2}}{\pi} V_{\text {bus }}
$$

Therefore, the equivalent resistance can be obtained.

$$
R_{e q u}=\frac{\alpha\left(R_{1} R_{2}+\omega^{2} M^{2}\right)}{\omega M-\alpha R_{1}}, \alpha=\frac{V_{b u s}}{d_{p v} V_{p v}} \ldots \ldots \ldots
$$

With the above analysis, $R_{\text {equ }} \in[5.06 \Omega(\mathrm{A}), 24.8 \Omega(\mathrm{B})]$. The equivalent load $R_{e q u}$ is shown in Fig.6(c), and then

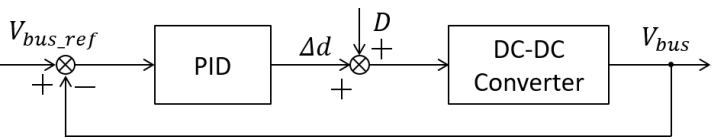

Fig. 7. DC-DC converter PID controller

based on Eq. (6), the WPT efficiency is shown in Fig. 6(d). The maximum efficiency is $91.11 \%$ at position C. With the PV curve in Fig. 3(a), when PV working point varies from position $\mathrm{A}$ to $\mathrm{B}$, the WPT efficiency is $\eta \in$ [85.13\%(B), 91.11\%(C)].

4.3 DC-DC Converter Controller Design In this paper, a bidirectional DC-DC converter is employed and the topology is shown in Fig. 2. Under working conditions, there is an equivalent working point in the control block as shown in Fig. 7. The values of DC-DC converter duty $d$, battery current $i_{b}$, DC bus voltage $v_{\text {bus }}$ and DC bus current $i_{b u s}$ can be changed into $D+\Delta d, I_{b}+\Delta i_{b}, V_{\text {bus }}+\Delta v_{\text {bus }}$ and $I_{\text {bus }}+\Delta i_{\text {bus }}$, respectively. Therefore, the following equation can be obtained.

$$
\left\{\begin{array}{l}
\frac{d}{d t}\left(\begin{array}{c}
\Delta i_{b} \\
\Delta v_{\text {bus }}
\end{array}\right)=A_{1}\left(\begin{array}{c}
\Delta i_{b} \\
\Delta v_{\text {bus }}
\end{array}\right)+B_{1}\left(\begin{array}{c}
\Delta d \\
\Delta i_{\text {bus }}
\end{array}\right) \\
\Delta v_{\text {bus }}=C_{1}\left(\begin{array}{c}
\Delta i_{b} \\
\Delta v_{\text {bus }}
\end{array}\right)
\end{array}\right.
$$

In the equation, the coefficient matrices are as follows.

$$
A_{1}=\left(\begin{array}{cc}
-\frac{R_{L 2}}{L_{2}} & \frac{D}{L_{2}} \\
-\frac{D}{C_{3}} & 0
\end{array}\right), \quad B_{1}=\left(\begin{array}{cc}
\frac{V_{b u s}}{L_{2}} & 0 \\
-\frac{I_{b}}{C_{3}} & \frac{1}{C_{3}}
\end{array}\right), C_{1}=\left(\begin{array}{ll}
0 & 1
\end{array}\right)
$$

Furthermore, $D$ can be obtained at the equivalent point.

$$
V_{b u s}=\frac{V_{b} \cdot D+R_{L 2} I_{b u s}}{D^{2}} .
$$

Therefore, based on the above equation, the DC-DC converter transfer function between the DC bus voltage and duty variations can be obtained in the following.

$$
P=\frac{\Delta v_{b u s}}{\Delta d}=\frac{b_{p 1} s+b_{p 0}}{s^{2}+a_{p 1} s+a_{p 0}} .
$$

Based on the transfer function, the DC-DC converter can be controlled with a PID controller in the following equation.

$$
C_{P I D}(s)=K_{p}+\frac{K_{i}}{s}+\frac{K_{d} s+1}{\tau s+1}
$$

Therefore, the PID parameters can be obtained based on the pole placement method, and then the DC bus voltage can be stabilized. 


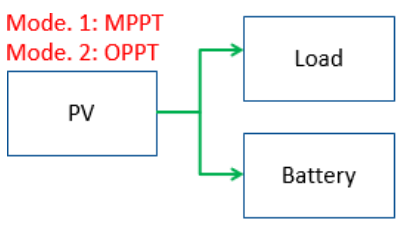

(a)

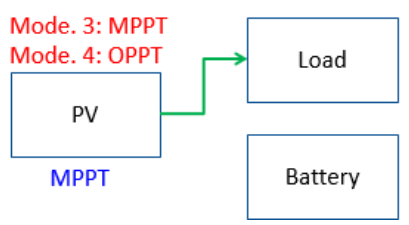

(b)

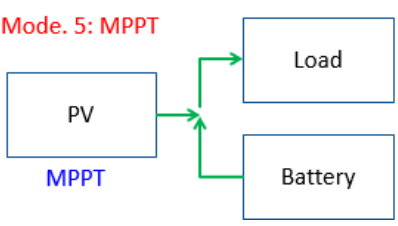

(c)

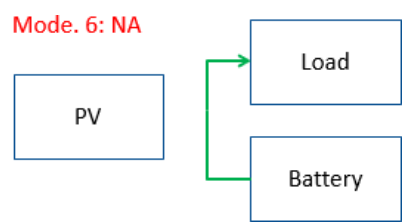

(d)

Fig. 8. System working modes (a) Mode 1 and 2. (b) Mode 3 and 4. (c) Mode 5. (d) Mode 6

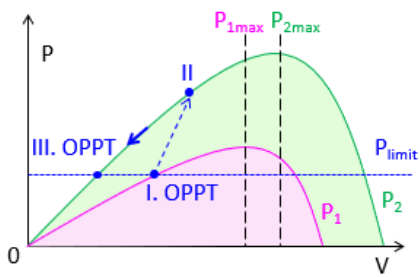

(a) Switch $A_{1}$

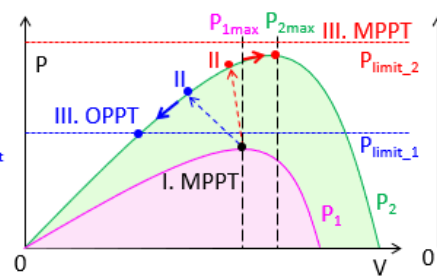

(b) Switch $\mathrm{A}_{2}$

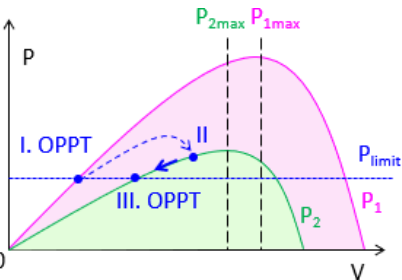

(c) Switch $B_{1}$

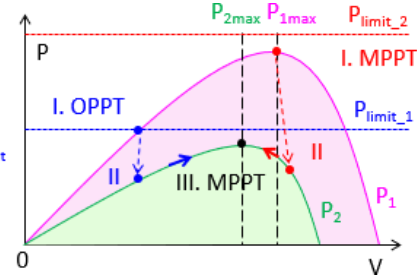

(d) Switch $\mathrm{B}_{2}$

Fig. 9. System working mode switch (a) Switch $A_{1}$. (b) Switch $A_{2}$. (c) Switch $B_{1}$. (d) Switch $B_{2}$

\section{Power Management Strategy Analysis}

Considering different solar irradiance conditions, to balance the PV output power and the required power of the rover side, the PV should be controlled with the MPPT or OPPT method. Furthermore, when the solar irradiance or load requirement varies, the system working mode should be automatically switched to the optimal mode. Therefore, in this section, the system working mode and mode switch will be analyzed.

5.1 System Working Mode Analysis Suppose that the generated powers from the PV are $P_{M P P T}$ and $P_{O P P T}$, and the load and battery powers are $P_{L}$ and $P_{b}$, respectively. As shown in Fig. 8, the 6 working modes can be obtained. In the following analysis, the battery voltage is assumed to be in the range of $\left[V_{L}, V_{H}\right]$.

Mode 1: The PV works in MPPT mode and the generated power is transferred to the battery and load. Furthermore, the battery charge current cannot exceed the charge current limit $I_{L}$ and the battery voltage should be lower than the preset upper limit $V_{H}$.

$$
P_{M P P T}=P_{L}+P_{b}, \quad\left|I_{b}\right| \leq\left|I_{L}\right|, \quad V_{L} \leq V_{b}<V_{H}
$$

Mode 2: The PV works in OPPT mode and the generated power is transferred to the battery and load. Furthermore, the battery charge current is equal to the charge current limit $I_{L}$, and because the battery voltage is lower than $V_{H}$, it can be charged.

$$
P_{O P P T}=P_{L}+P_{b}, \quad\left|I_{b}\right|=\left|I_{L}\right|, \quad V_{L} \leq V_{b}<V_{H}
$$

Mode 3: When the battery voltage is charged up to be the upper limit, namely $V_{b}=V_{H}$, the battery can be regarded to have been fully charged. In this case, it will be switched off from the DC bus. The PV output power in MPPT mode is equal to the required power of the load.

$$
P_{M P P T}=P_{L}, \quad\left|I_{b}\right|=0, \quad V_{b}=V_{H}
$$

Mode 4: The battery has been fully charged and it is switched off from the DC bus. As the solar irradiance is too strong the PV works in OPPT mode to output the required power to the load.

$$
P_{O P P T}=P_{L}, \quad\left|I_{b}\right|=0, \quad V_{b}=V_{H} \ldots \ldots \ldots \ldots
$$

Mode 5: The solar irradiance is not strong enough, and then both the PV and battery should output power to drive the load. In this mode, the PV works in MPPT mode and the battery discharge current should be lower than $I_{H}$. Furthermore, the battery voltage should be higher than the preset lower limit $V_{L}$.

$$
P_{M P P T}+P_{b}=P_{L}, \quad I_{b} \leq I_{H}, \quad V_{L}<V_{b} \leq V_{H} \cdots
$$

Mode 6: During lunar night, because there is no solar irradiance, the PV stops working. The battery is only power source to the load.

$$
P_{b}=P_{L}, \quad I_{b} \leq I_{H}, \quad V_{L}<V_{b} \leq V_{H}
$$

Based on the above analysis, the solar irradiance, $I_{L}, I_{H}$, $V_{L}$ and $V_{H}$ are several key factors that determine the system MPPT or OPPT mode.

5.2 System Working Mode Switch Analysis Under working conditions, the solar irradiance and load power requirements are not constant. To balance the power supply and requirement, the system should switch working modes to control the PV to output the optimal power. The required power of the load and battery is named as $P_{\text {limit }}$, and then the system working mode switching is investigated in Fig. 9.

Switch $A_{1}$ : In Fig. 9(a), initially, the system works at the position I at the PV output power $P_{1}$ curve in OPPT mode. When the solar irradiance increases, the PV curve will change from $P_{1}$ to $P_{2}$. Because at the moment when the PV output power changes the buck converter duty $d_{I}$ cannot be changed instantaneously, the system working point is shifted to position II at $P_{2}$ curve with $d_{I}$. Because at the position II the PV output power $P_{I I}>P_{\text {limit }}$, the system will still work in the OPPT mode. Therefore, the buck converter duty will be gradually tuned from $d_{I}$ to $d_{I I I}$ to move the system working point to the position III at which point the PV output power is equal to $P_{\text {limit }}$.

Switch $A_{2}$ : In Fig. 9(b), $P_{\text {limit }}$ is increased to $P_{\text {limit }}$, and 


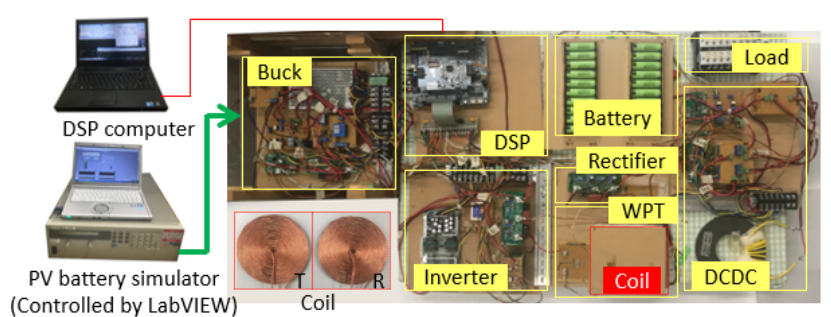

(a)

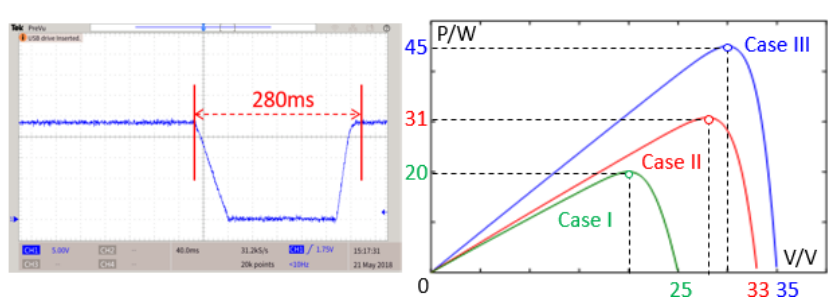

(b)

(c)

Fig. 10. Experimental consitions (a) Experimental platform. (b) PV simulator output drop. (c) Three cases of PV simulator states

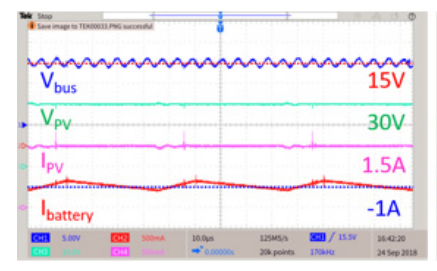

(a) Mode 1

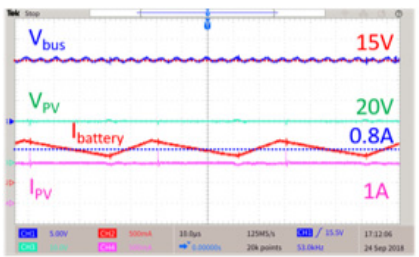

(e) Mode 5

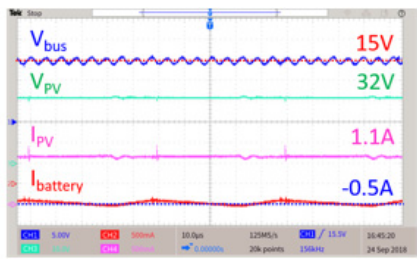

(b) Mode 2

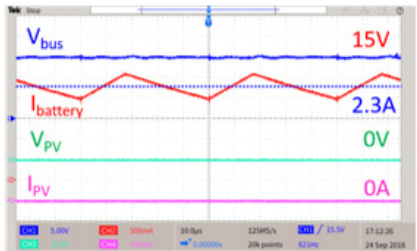

(f) Mode 6

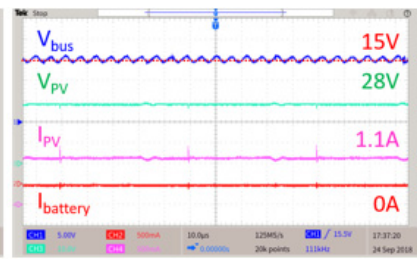

(c) Mode 3

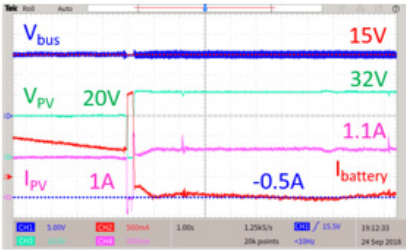

(g) Switch A

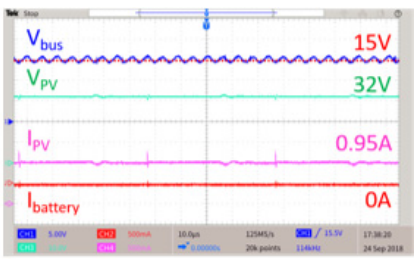

(d) Mode 4

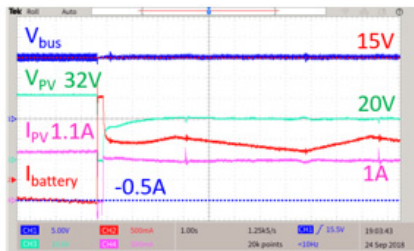

(h) Switch B

Fig. 11. Experimental results of 6 working modes (a) Mode 1. (b) Mode 2. (c) Mode 3. (d) Mode 4. (e) Mode 5. (f) Mode 6. (g) Switch $A_{2}$. (h) Switch $B_{2}$

the PV output power also rises from $P_{1}$ to $P_{2}$. When the PV output power changes from $P_{1}$ to $P_{2}$, because $P_{I I}>P_{\text {limit } 1}$, the system will still work in the OPPT mode. Therefore, the system working point will be moved from the position II to III gradually in the OPPT mode.

Switch $A_{3}$ : In Fig. 9(b), $P_{\text {limit }}$ is increased to $P_{\text {limit }}$, and the PV output power also rises from $P_{1}$ to $P_{2}$. When the PV output power changes from $P_{1}$ to $P_{2}$, because $P_{I I}<P_{\text {limit } 2}$, the system will work in the MPPT mode. Therefore, the system working point will be moved from the position II to III gradually in the MPPT mode.

Switch $B_{1}$ : In Fig. 9(c), initially, the system works at the position I at the PV output power $P_{1}$ curve in OPPT mode. When the solar irradiance decreases, the PV curve will change from $P_{1}$ to $P_{2}$. Because at the moment when the PV output power changes the buck converter duty $d_{I}$ cannot be changed instantaneously, the system working point is shifted to position II at $P_{2}$ curve with $d_{I}$. Because at the position II the PV output power $P_{I I}>P_{\text {limit }}$, the system will still work in the OPPT mode. Therefore, the buck converter duty will be gradually tuned from $d_{I}$ to $d_{I I I}$ to move the system working point to the position III at which point the PV output power is equal to $P_{\text {limit }}$.

Switch $B_{2}$ : In Fig. 9(d), $P_{\text {limit }}$ is increased to $P_{\text {limit }}$, and the PV output power decreases from $P_{1}$ to $P_{2}$. When the PV output power changes from $P_{1}$ to $P_{2}$, because $P_{I I}<P_{\text {limit } 1}$, the system will work in the MPPT mode. Therefore, the system working point will be moved from the position II to III gradually in the MPPT mode.

Switch $B_{3}$ : In Fig. 9(d), $P_{\text {limit }}$ is increased to $P_{\text {limit }}$, and the PV output power decreases from $P_{1}$ to $P_{2}$. When the PV output power changes from $P_{1}$ to $P_{2}$, because $P_{I I}<P_{\text {limit } 2}$, the system will work in the MPPT mode. Therefore, the system working point will be moved from the position II to III gradually in the MPPT mode.

\section{Experiment Prototype and Analysis Result}

The experimental prototype is established as shown in Fig. 10. The battery voltage is $10 \mathrm{~V}$. The inverter frequency is $85 \mathrm{kHz}$. The DC bus voltage reference is set as $15 \mathrm{~V}$. Furthermore, $\left[V_{L}, V_{H}\right]=[9 \mathrm{~V}, 11 \mathrm{~V}]$ and $I_{H}=3 \mathrm{~A}$. The PV simulator is Keysight E4350B. However, when the PV simulator working mode switches, due to the hardware limitation there is a 280 ms output power drop as shown in Fig. 10(b). Furthermore, the PV works in 3 cases as shown in Fig. 10(c). The 6 working modes are shown in Fig. 11.

Mode 1: The PV works in case I and $I_{L}=-2 \mathrm{~A}$. Because $I_{L}$ is low enough, the MPPT method can be conducted. The PV output voltage is $V_{p v}=30 \mathrm{~V}$ indicating MPPT control has been successfully conducted. The battery discharge current is $I_{b}=-1 \mathrm{~A}$, and the DC bus voltage is $V_{b u s}=15 \mathrm{~V}$. Furthermore, there is a $170 \mathrm{kHz}$ ripple of the DC bus voltage, wihch is caused by the current loop of the rectifier and the DC bus. When the $85 \mathrm{kHz}$ receiver current flows through the rectifier it will be transformed into $170 \mathrm{kHz}$, and then the DC bus voltage is influenced to generate the ripple.

Mode 2: The PV works in case I and $I_{L}=-0.5 \mathrm{~A}$. Therefore, the PV should work with the OPPT method. $V_{p v}$ and $I_{p v}$ are $32 \mathrm{~V}$ and $1.1 \mathrm{~A}$, respectively, and then $P_{O P P T}=35.2 \mathrm{~W}$. Furthermore, $I_{b}=-0.5 \mathrm{~A}$ indicates that the proposed OPPT method is effective.

Mode 3: The battery is switched off, and $V_{b u s}$ is controlled 
by a PV buck converter. Therefore, when $P_{M P P T}$ is just right for the load, MPPT control should be conducted. In Fig. 11(c), the PV works in case II and $V_{p v}=28 \mathrm{~V}$, indicating that that the MPPT control has been conducted.

Mode 4: When $P_{M P P T}$ is excessive, the system should change to OPPT mode. In Fig. 11(d), the PV works in case I. $V_{p v}=32 \mathrm{~V}$ and the output power is approximately $31 \mathrm{~W}$, indicating the OPPT method has been conducted.

Mode 5: The PV and battery should output power together to the load when the solar irradiance decreases. In Fig. 11(e), PV works in case III and $V_{p v}=20 \mathrm{~V}$ indicating that the MPPT control has been conducted. Furthermore, $I_{b}=0.8 \mathrm{~A}$ which is lower than $I_{H}$.

Mode 6: When it turns to lunar night, the PV stops working and only the battery outputs power to the DC bus. As shown in Fig. 11(f), the battery output current is $I_{b}=2.3 \mathrm{~A}$.

Switch $A_{2}$ : When the PV changes from case II to I, the system should moves from MPPT to OPPT mode. Initially, the system works in MPPT mode, when it changes because of the output power drop, there is a pulse range as shown in Fig. 11(g). In this pulse, the PV output voltage and current become zero and the battery outputs power to stablize the DC bus voltage at $15 \mathrm{~V}$. When the pulse ends, system rapidly switches to OPPT mode with $I_{b}=I_{L}=-0.5 \mathrm{~A}$.

Switch $B_{2}$ : The PV changes from case I to II, and before the change system works in OPPTmode. Similarly there is a pulse range and the DC bus voltage is also stablized. After the pulse system switches to the MPPT mode rapidly.

The system efficiency is related to the system power, and the efficiency in Mode 1 is analyzed. Based on Fig. 2, the efficiency from the PV to the DC bus is $\eta_{s y s}=75 \%$, and the buck converter efficiency is $\eta_{\text {buck }}=87 \%$. The efficiency of the inverter, WPT module and rectifier $\eta_{I W R}=86 \%$, and the DC-DC converter efficiency is $\eta_{D C}=88 \%$.

\section{Conclusion}

In this paper, a WPT system has been proposed for a lunar rover to avoid heat leakage during lunar night. Furthermore, considering the variation in the solar irradiance during lunar day, a power management system has also been analyzed and explored. The system working state is divided into 6 modes and based on different solar irradiances, the working mode can be switched automatically. The system efficiency approaches approximately $75 \%$ with $45 \mathrm{~W}$, and in this case, the efficiency of the buck converter is $87 \%$. The efficiency of the WPT module with an inverter and rectifier is approximately $86 \%$. The DC-DC converter efficiency is approximately $88 \%$. With the proposed wireless power system, the heat leakage caused by the conventional wire connection of lunar rover can be completely avoided, and then during lunar night, there will be no extra thermal control requirement for the system battery. Furthermore, under the control of the proposed power management strategy, the proposed lunar rover WPT system working mode can be automatically switched with the solar irradiance variation to balance the power supply and requirement. Therefore, in this paper, the proposed WPT system has been verified to reduce the battery volume and it will greatly promot the lunar rover development in the future.

\section{References}

( 1 ) J. Sạiadek: "Space robotics and its challenges", Aerospace robotics, Springer, Berlin, Heidelberg, pp.1-8 (2013)

( 2 ) M.L. Tuballa and M.L. Abundo: "A review of the development of Smart Grid technologies", Renew. Sust. Energ. Rev., Vol.59, pp.710-725 (2016)

( 3 ) C. Liu, K.T. Chau, and X. Zhang: "An efficient windphotovoltaic hybrid generation system using doubly excited permanent-magnet brushless machine", IEEE Trans. on Ind. El., Vol.57, No.3, pp.831-839 (2009)

( 4 ) A.W. Leedy, G. Liping, and A.A. Kennedy: "A constant voltage MPPT method for a solar powered boost converter with DC motor load", 2012 Proceedings of IEEE Southeastcon, pp.1-6 (2012)

( 5 ) D. Verma, S. Nema, A.M. Shandilya, and S.K. Dash: "Maximum power point tracking (MPPT) techniques: Recapitulation in solar photovoltaic systems", Renew. Sust. Energ. Rev., Vol.54, pp.1018-1034 (2016)

( 6 ) N. Kumar, I. Hussain, B. Singh, and B. Panigrahi: "Framework of maximum power extraction from solar PV panel using self predictive perturb and observe algorithm", IEEE Trans. Sustain. Energy, Vol.9, No.2, pp.895-903 (2017)

( 7 ) N. Femia, G. Petrone, G. Spagnuolo, and M. Vitelli: "Optimization of perturb and observe maximum power point tracking method", IEEE Trans. on Pow. El., Vol.20, No.4, pp.963-973 (2005)

( 8 ) F. Liu, S. Duan, F. Liu, B. Liu, and Y. Kang: “A variable step size INC MPPT method for PV systems", IEEE Trans. on Ind. El., Vol.55, No.7, pp.26222628 (2008)

( 9 ) Q. Mei, M. Shan, L. Liu, and J.M. Guerrero: "A novel improved variable step-size incremental-resistance MPPT method for PV systems", IEEE Trans. on Ind. El., Vol.58, No.6, pp.2427-2434 (2010)

(10) K. Ishaque, Z. Salam, M. Amjad, and S. Mekhilef: "An improved particle swarm optimization (PSO) based MPPT for PV with reduced steady-state oscillation", IEEE Trans. on Pow. El., Vol.27, No.8, pp.3627-3638 (2012)

(11) Ahmed A. Zaki Diab and H. Rezk.: "Global MPPT based on flower pollination and differential evolution algorithms to mitigate partial shading in building integrated PV system", Sol. Energy, Vol.157, pp.171-186 (2017)

(12) D.F. Teshome, C.H. Lee, Y.W. Lin, and K.L. Lian: "A modified firefly algorithm for photovoltaic maximum power point tracking control under partial shading", IEEE Trans. Emerg. Sel. Topics Power Electron., Vol.5, No.2, pp.661-671 (2016)

(13) K. Kusaka and J. Itoh: "Development Trends of Inductive Power Transfer Systems Utilizing Electromagnetic Induction with Focus on Transmission Frequency and Transmission Power", IEEJ J. Ind. Appl., Vol.6, No.5, pp.328-339 (2017)

(14) T. Imura and Y. Hori: "Maximizing air gap and efficiency of magnetic resonant coupling for wireless power transfer using equivalent circuit and Neumann formula", IEEE Trans. on Ind. El., Vol.58, No.10, pp.4746-4752 (2011)

(15) G. Lovison, T. Imura, H. Fujimoto, and Y. Hori: "Secondary-side-only Phaseshifting Voltage Stabilization Control with a Single Converter for WPT Systems with Constant Power Load", IEEJ J. Ind. Appl., Vol.8, No.1, pp.66-74 (2019)

(16) Z. Zhang, K.T. Chau, C. Qiu, and C. Liu: "Energy encryption for wireless power transfer", IEEE Trans. on Pow. El., Vol.30, No.9, pp.5237-5246 (2014)

(17) V.D. Doan, H. Fujimoto, T. Koseki, T. Yasuda, H. Kishi, and T. Fujita: "Simultaneous Optimization of Speed Profile and Allocation of Wireless Power Transfer System for Autonomous Driving Electric Vehicles", IEEJ J. Ind. Appl., Vol.7, No.2, pp.189-201 (2018)

(18) S. Li and C.M. Chunting: "Wireless power transfer for electric vehicle applications", IEEE Trans. Emerg. Sel. Topics Power Electron., Vol.3, No.1, pp.4-17 (2014)

(19) V.D. Doan, H. Fujimoto, T. Koseki, T. Yasuda, H. Kishi, and T. Fujita: "Simultaneous optimization of speed profile and allocation of wireless power transfer system for autonomous driving electric vehicles", IEEJ J. Ind. Appl., Vol.7, No.2, pp.189-201 (2018)

(20) S. Rao and J-C. Chiao: "Body electric: Wireless power transfer for implant applications”, IEEE Microw. Mag., Vol.16, No.2, pp.54-64 (2015)

(21) H.J. Kim, H. Hirayama, S. Kim, K.J. Han, R. Zhang, and J.W. Choi: "Review of near-field wireless power and communication for biomedical applications", IEEE Access, Vol.5, pp.21264-21285 (2017)

(22) A. Kim, M. Ochoa, R. Rahimi, and B. Ziaie : "New and emerging energy sources for implantable wireless microdevices", IEEE Access, Vol.3, pp.8998 (2015)

(23) W. Na, et al.: "Energy-efficient mobile charging for wireless power transfer in Internet of Things networks", IEEE Internet Things J., Vol.5, No.1, pp.79-92 (2017)

(24) W. Na, J. Park, C. Lee, K. Park, J. Kim, and S. Cho: "Distributed wireless 
power transfer system for internet of things devices", IEEE Internet Things J., Vol.5, No.4, pp.2657-2671 (2018)

(25) M.M. Rana, W. Xiang, E. Wang, X. Li, and B.J. Choi: "Internet of Things infrastructure for wireless power transfer systems", IEEE Access, Vol.6, pp.19295-19303 (2018)

(26) W. Zhang and C.M. Chunting: "Compensation topologies of high-power wireless power transfer systems", IEEE Trans. Veh. Technol., Vol.65, No.6, pp.4768-4778 (2015)

(27) G.R.C. Mouli, P. Bauer, and M. Zeman: "System design for a solar powered electric vehicle charging station for workplaces", Appl. Energ., Vol.168, pp.434-443 (2016)

(28) L. Fangrui, D. Shanxu, L. Fei, L. Bangyin, and K. Yong: "A variable step size INC MPPT method for PV systems", IEEE Trans. on Ind. El., Vol.55, No.7, pp.2622-2628 (2008)

(29) A. Loukriz, H. Mourad, and M. Sabir: "Simulation and experimental design of a new advanced variable step size Incremental Conductance MPPT algorithm for PV systems", ISA transactions, Vol.62, pp.30-38 (2016)

(30) N.E. Zakzouk, A.K. Abdelsalam, A.A. Helal, and B.W. Williams: "Modified variable-step incremental conductance maximum power point tracking technique for photovoltaic systems", IECON 2013-39th Annual Conference of the IEEE Industrial Electronics Society, IEEE (2013)

Bingcheng Ji (Non-member) received the B.S. and M.S. degrees

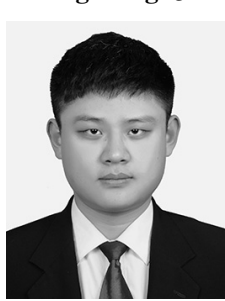
in electrical engineering from Dalian University of Technology, Dalian, China, in 2011 and 2015, respectively. He is currently working toward the Ph.D. degree in the Graduate School of Frontier Sciences, The University of Tokyo, Chiba, Japan. His research interests include wireless power transfer, PV MPPT control and power electronics.

Katsuhiro Hata

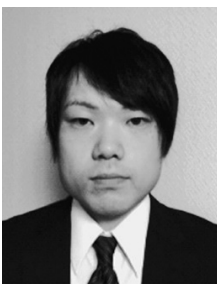

(Member) received the M.S. and Ph.D. degrees from the University of Tokyo, Japan in 2015 and 2018, respectively. In 2016, he joined the Japan Society for the Promotion of Science (JSPS), Japan, as a research fellow. His research interests include power electronics and its application to in-motion wireless charging of electric vehicles. He is a member of the Institute of Electrical Engineers of Japan, the Society of Automotive Engineers of Japan, and the Institute of Electronics, Information and Communication Engineers,

Japan.

Takehiro Imura (Member) receiverd the bachelors degree in elec-

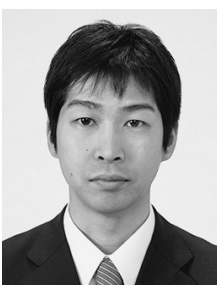
trical and electronics engineering from Sophia University, Tokyo, Japan, in 2005, and the M.E. degree in electronic engineering and the D.Eng. degree in electrical engineering from The University of Tokyo, Tokyo, in 2007 and 2010, respectively. He joined the Department of Advanced Energy, Graduate School of Frontier Sciences, University of Tokyo, as a Research Associate, where since 2015, he has been a Project Lecturer. He is currently investigating wireless power transfer for EV using electromagnetic resonance coupling.
Yoichi Hori (Fellow) received the B.S., M.S., and Ph.D. degrees in

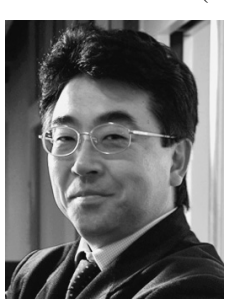
electrical engineering from the University of Tokyo, Tokyo, Japan, in 1978, 1980, and 1983, respectively. In 2000, he became a Professor at the University of Tokyo, and where in 2008, he moved to the Department of Advanced Energy, Graduate School of Frontier Sciences. His research fields are control theory and its industrial applications in motion control, mechatronics, robotics, and electric vehicles. Dr. Hori received the Best Transactions Paper Award from the IEEE Transactions on Industrial Electronics in 1993 and 2001, and the 2011 Achievement Award from the Institute of Electrical Engineers of Japan (IEE-Japan). He was the President of the Industry Applications Society the IEEJ, the President of Capaciotrs Forum, and the Chairman of the Motor Technology Symposium of the Japan Manahement Association, and the Director on Technological Develipment of SAEJapan.

Shuhei Shimada (Non-member) received the B.S. and M.S. degrees

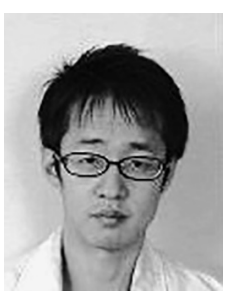
in electrical engineering from Tokyo University of Science in 2007 and 2009 respectively. He is currently developing satellite power systems and small batteries in JAXA R\&D directorate. He researches wireless power supply system for spacecraft.

Osama Kawasaki (Non-member) received the B.S. and M.S. degrees

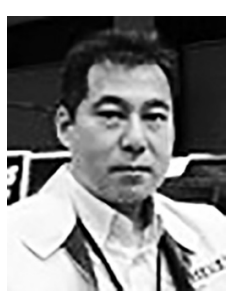
in nuclear engineering from the Osaka University, Osaka, Japan, in 1989 and 1991 respectively. After he entered JAXA, he engaged in the development of the electrical power system of Japanese unmanned transfer vehicle to the International Space Station, HTV, and the asteroid explorer, Hayabusa2.He currently researches the space application of wireless power transfer technique in $R \& D$ directorate. 